Medi um chai $n$ fatty aci ds ( MCFA) product i on through anaer obi $c$ fer ment at i on usi ng $\mathrm{Cl}$ ost ri di um kl uyveri : Effect of et hanol and acet at e

\begin{tabular}{|l|l|}
\hline 著者 & $\begin{array}{l}\text { REDDY M Venkat eswar, MOHAN S. Venkat a, CHANG } \\
\text { Young- Cheol }\end{array}$ \\
\hline $\begin{array}{l}\text { j our nal or } \\
\text { publ i cat i on t i t l e }\end{array}$ & Appl i ed Bi ochemi st ry and Bi ot echnol ogy \\
\hline vol une & 185 \\
\hline number & 3 \\
\hline page r ange & 594605 \\
\hline year & $2018-07$ \\
\hline URL & ht t p: //hdl . handl e. net /10258/00009924 \\
\hline
\end{tabular}




\title{
Medium chain fatty acids (MCFA) production through anaerobic fermentation using Clostridium kluyveri: Effect of ethanol and acetate
}

\author{
M. Venkateswar Reddy ${ }^{* 1}$, S. Venkata Mohan ${ }^{2}$, Young-Cheol Chang ${ }^{* 1}$ \\ ${ }^{1}$ Department of Applied Sciences, College of Environmental Technology, \\ Muroran Institute of Technology, 27-1 Mizumoto, Muroran, 050-8585, Japan. \\ ${ }^{2}$ Bioengineering and Environmental Sciences (BEES), CSIR-Indian Institute of Chemical \\ Technology (CSIR-IICT), Hyderabad 500007, India. \\ * Corresponding author. E-mail: ychang@mmm.muroran-it.ac.jp, Tel \& Fax: +81-143-46-5757 \\ Co-corresponding author. E-mail: $\underline{\text { mvr_234@yahoo.co.in }}$
}

\begin{abstract}
Medium chain fatty acids (MCFA) are saturated monocarboxylic acids, can be used as antimicrobials, corrosion inhibitors, precursors in biodiesel, and bioplastics production. In the present study, MCFA production was evaluated with acetate and ethanol using the bacteria Clostridium kluyveri. Effects of substrate, electron donor, and methane inhibitor on MCFA production were evaluated. Bacteria successfully converted the ethanol and acetate to butyrate (C4), caproate (C6), and caprylate (C8) by chain elongation process. The highest concentrations of butyrate $(4.6 \mathrm{~g} / \mathrm{l})$, caproate $(3.2 \mathrm{~g} / \mathrm{l})$, and caprylate $(0.5 \mathrm{~g} / \mathrm{l})$ were obtained under methane inhibition conditions than other conditions. The productions of butyrate and caproate were 1.6 and 1.48 times higher than those under methane inhibition conditions respectively. Results denoted that the bacteria $C$. kluyveri can be used for conversion of acetate and ethanol into useful products like butyrate and caproate.
\end{abstract}

Keywords: Clostridium kluyveri; medium chain fatty acids (MCFA); butyrate; anti-microbials; caproate. 


\section{INTRODUCTION}

Anaerobic digestion technology converts organic waste into the methane which is an energy carrier. But, methane is not a perfect transportation fuel and the economic value of methane is too low to support extensive adaptation [1]. Methanogenesis need to be inhibit for higher production of medium chain fatty acids (MCFA) [1]. One of the MCFA, caproate (C6) was commodity chemical which can be used for the production of lubricants, personal care products, animal feed additives, and antimicrobials. Caproate can be converted to a fuel by a series of ketonization and dehydrogenation processes to generate alkanes. These alkanes can be blended with other chemicals to produce biodiesel. Caproate extraction is easy due to its low maximum solubility and with a much lower energy investment compared to distillation of soluble ethanol [1]. Caproate also has excellent applications as a chemical precursor for flavors and as aviation fuels [2]. Caproate has 20 times more value than methane and two times more value than ethanol. Ethanol is the predominant chemical used as electron donor for the production of MCFA. Besides ethanol [3], other reduced substrates such as polyols [4], and lactate [5] have also been utilized for the production of caproate.

Chain elongation has been recently reported in microbial electrosynthesis systems (MES) by researchers. Schievano et al., (2016) and Roy et al., (2016) reported about chemicals production by chain elongation process in electro-fermentation and bioelectrochemical systems respectively $[6,7]$. MCFA production was evaluated by researchers using co-cultures and mixed cultures. Kenealy et al. reported the production of caproate from cellulose and ethanol with a definite coculture [13]. Grootscholten et al. used mixed cultures to produce MCFA from municipal waste and ethanol in a single stage reactor [3]. In our previous studies we evaluated the production of MCFA 
with synthetic waste [8] and food waste [9]. Influence of substrate and electron donor on MCFA production was also evaluated using enriched mixed bacterial culture [8].

Many literature reports were available about MCFA production using mixed cultures, but very few pure bacterial cultures were explored to produce MCFA even though they have high potentiality. Clostridium kluyveri is one of the bacteria which have the high potential to produce MCFA through chain elongation. C. kluyveri is unique among the Clostridia, it grows anaerobically on ethanol and acetate as sole energy sources, and produce butyrate, caproate, and hydrogen as fermentation products [10]. C. kluyveri is a model organism in the early 1950s for the study of fatty acid synthesis [10]. It is well known for its reversed $\beta$-oxidation metabolism, converting SCFA with ethanol into MCFA and hydrogen. This bacterium stimulates the production of MCFA in the rumen [11]. Diender et al. reported the establishment of a synthetic co-culture consisting of $C$. autoethanogenum and C. kluyveri [12]. Together, these bacteria can convert carbon monoxide and syngas in to butyrate, caproate and their respective alcohols. The co-culture can grow using solely carbon monoxide or syngas as a substrate, and in the presence of acetate production rates were enhanced. By considering the potentiality of C. kluyveri, in the present study we evaluated MCFA production using this bacterium. Influence of methane inhibitor, electron donor, and substrate were also evaluated. Since acetate is the main intermediate product of anaerobic digestion, we used acetate as substrate in the synthetic medium in our feasibility study. Production of butyrate (C4), caproate (C6), and caprylate (C8) were demonstrated for 33 days using C. kluyveri in four types of experimental conditions, i.e., methane inhibition (EXP1), no-inhibition of methane (EXP2), no ethanol addition (EXP3), and no acetate addition (EXP4). Produced SCFA, MCFA and biogas were analysed at different time intervals using high pressure liquid chromatography (HPLC) and gas chromatography (GC) respectively. 


\section{MATERIALS AND METHODS}

\section{C. kluyveri}

Clostridium kluyveri (NBRC 12016) was collected from the Biological Resource Center, National Institute of Technology and Evaluation (NBRC), Japan. C. kluyveri is an anaerobic, motile, grampositive bacterium from the family of Clostridiaceae, and belongs to Firmicutes division. Limited information was available about efficiency of this bacterium for the production of fatty acids through anaerobic fermentation.

\section{Medium}

The growth medium for $C$. kluyveri was used as suggested by NBRC with some modifications (medium 213). The growth medium contained -8 g sodium acetate, 1 g yeast extract, 27 g ethanol, 2 g $\left(\mathrm{NH}_{4}\right)_{2} \mathrm{SO}_{4}, 2 \mathrm{~g} \mathrm{~K}_{2} \mathrm{HPO}_{4}, 0.4 \mathrm{~g} \mathrm{NaH}_{2} \mathrm{PO}_{4}, 0.10$ g NaCl, 0.2 g $\mathrm{MgSO}_{4} .7 \mathrm{H}_{2} \mathrm{O}, 0.05$ g CaCl, 8.3 mg $\mathrm{FeCl}_{3} .6 \mathrm{H}_{2} \mathrm{O}, 1.4 \mathrm{mg} \mathrm{MnCl}_{2} .4 \mathrm{H}_{2} \mathrm{O}, 1.2 \mathrm{mg} \mathrm{Na} \mathrm{MoO}_{4} .2 \mathrm{H}_{2} \mathrm{O}$, and $1 \mathrm{mg} \mathrm{ZnCl}_{2}$ per one liter of deionized water. Medium pH was adjusted to 7 and autoclaved before adding to the serum bottles. Ethanol was added after sterilization.

\section{Growth curve analysis}

A loop of C. kluyveri strain was initially inoculated into $10 \mathrm{ml}$ of growth medium in $50 \mathrm{ml}$ serum bottles and kept in shaking incubator at $120 \mathrm{rpm}$ under dark condition at $37{ }^{\mathrm{O}} \mathrm{C}$ for 2 days. For growth experiments, $2 \mathrm{ml}$ of the pre-grown culture was inoculated into different serum bottles (total volume-120 ml) containing $40 \mathrm{ml}$ of growth medium. After adding growth medium and bacteria, serum bottles were sealed with a rubber stopper and aluminum sealer. Headspace was flushed with $\mathrm{N}_{2}$ at $0^{\text {th }}$ day for all the experiments and all the bottles were kept in temperature controlled shaking incubator at the shaking speed of 120 rpm for a period of 15 days. Samples 
were collected at different time intervals, the growth was monitored spectrometrically by measuring the absorbance at $600 \mathrm{~nm}$ using UV-spectrometer (UV-1800, Shimadzu, Japan).

\section{MCFA production}

For SCFA and MCFA production, $2 \mathrm{ml}$ of the pre-grown C. kluyveri was inoculated into different serum bottles containing medium. Triplicate experiments were performed in this study. Serum bottles of $120 \mathrm{ml}$ with butyl rubber stoppers and aluminium caps were used for all the experiments. Each bottle contained $40 \mathrm{ml}$ of growth medium. MCFA production from acetate was stimulated by addition of ethanol as electron donor. Before inoculation, the $\mathrm{pH}$ was adjusted to 7 with $5 \mathrm{M}$ $\mathrm{NaOH}$ solution. After inoculation with bacteria, the bottles were closed and capped. The headspace was flushed with nitrogen for 5 minutes. The bottles were incubated at $37^{\circ} \mathrm{C}$ in a rotating shaker at 120 rpm for 33 days. Control experiments were also carried out without adding bacteria. Liquid samples were anaerobically taken and collected in a reaction tube. The liquid samples were centrifuged (5 min, $8000 \times g$ ) and used for SCFA and MCFA analysis as mentioned below. For MCFA production four types of experiments were carried out. EXP1 was conducted by adding acetate, ethanol, and BESA in the medium. EXP2 was carried out by adding acetate and ethanol in the medium. BESA was not added in the medium in order to know the influence of BESA on MCFA production. EXP3 was led by adding only acetate. Ethanol and BESA were not added in the medium to find out the influence of acetate on MCFA production. EXP4 was conducted by adding only ethanol. Acetate and BESA were not added in the medium to identify the influence of ethanol on MCFA production.

\section{Analysis}

The concentrations of butyrate and ethanol at different time intervals were analyzed using high pressure liquid chromatography (HPLC, Shimadzu) with a refractive index (RI detector) and Shim- 
pack SCR-102 (H) column (Shimadzu, Kyoto, Japan). MCFA were estimated by transesterification method. For transesterification of MCFA, boron trifluoride $\left(\mathrm{BF}_{3}\right)$ in methanol (14\% w/v, GL series Inc. Japan) was used. Gas samples from the headspace were analyzed at different time intervals for identification of $\mathrm{H}_{2}, \mathrm{CH}_{4}$, and $\mathrm{CO}_{2}$ by GC (GC-14B, Shimadzu Co., Japan). All the analysis was carried out according to the methods described by Reddy et al., (2017) [8].

\section{RESULTS AND DISCUSSION}

\section{Growth curve}

C. kluyveri was cultivated in growth medium at $37^{\circ} \mathrm{C}$ by supplementing with acetate/or ethanol /or mixture of both acetate and ethanol. Carbon source present in the medium showed significant influence on the bacterial growth (Fig. 1). Among the four experiments, bacteria showed higher growth in EXP4 followed by EXP1, EXP2 and EXP3. Initially (up to $3^{\text {rd }}$ day) bacteria showed lower growth in all the experiments, after $3^{\text {rd }}$ day it showed good growth. Bacteria showed maximum growth at different time intervals in different experiments based on the type of carbon source. Bacteria showed maximum growth at $5^{\text {th }}$ day in EXP4 (OD-0.395) and EXP3 (0.251), $8^{\text {th }}$ day in EXP1 (0.35) and EXP2 (0.31). When the growth was compared at $8^{\text {th }}$ day, bacteria grown in EXP4 showed highest growth, i.e., 1.06 times higher than EXP1, 1.18 times higher than EXP2, and 1.73 times higher than EXP3. Bacteria grown only with acetate showed lower growth. Bacteria grown with mixture of substrates showed late decline phase i.e., decline phase started after $8^{\text {th }}$ day.

\section{Acetate utilization}

\section{Fig. 1}

Acetate concentration at different time intervals were analyzed using HPLC for all the experimental conditions (Fig. 2). HPLC results showed that bacteria utilized the acetate present in 
the medium within 33 days for its growth and MCFA production. Little amount of acetate (0.98 g/l on day 1) was observed in the EXP4 (acetate not supplemented in the medium), might be due to the presence of acetate in pre-culture medium or production of acetate from ethanol by $C$. kluyveri. Barker et al. (1945) reported that for every five molecules of ethanol that are used for elongation by C. kluyveri, one molecule is oxidized to acetate for generating metabolic energy [13]. After 1-day C. kluyveri utilized the produced acetate for its growth, so the acetate concentration showed continuous decrement. Acetate concentration continuously decreased from $3^{\text {rd }}$ day $(0.93$ $\mathrm{g} / \mathrm{l})$ to $15^{\text {th }}$ day $(0.29 \mathrm{~g} / \mathrm{l})$. At $20^{\text {th }}$ day acetate was not observed; it indicates that $C$. kluyveri completely utilized acetate for its growth. Experiments conducted with only acetate (EXP3) showed continuous decrement of acetate. C. kluyveri showed $43 \%$ removal of acetate at $6^{\text {th }}$ day, $76 \%$ removal at $15^{\text {th }}$ day, and $98 \%$ removal at $20^{\text {th }}$ day. EXP3 showed highest acetate removal than other experiments due to the presence of single carbon source.

Experiments conducted with mixture of acetate and ethanol (EXP1 \& EXP2) showed continuous decrement of acetate. EXP2 showed highest removal of acetate than EXP1, indicates that BESA addition does not showed influence on the acetate removal. Acetate removal by C. kluyveri was in increasing pattern with increasing time in EXP2 i.e., $41 \%$ removal at $6^{\text {th }}$ day, $59 \%$ removal at $15^{\text {th }}$ day, and $96 \%$ removal at $20^{\text {th }}$ day. Bacteria in EXP1 also showed good removal of acetate at $24^{\text {th }}$ day (91\%) followed by $20^{\text {th }}$ day (89\%), and $6^{\text {th }}$ day (23\%). Acetate concentration showed gradual decrement due to utilization of acetate for butyrate and MCFA production. Vasudevan et al. (2014) used two years old enriched mixed culture and C. ljungdahlii effluent contains acetic acid ( $2.3 \mathrm{~g} / \mathrm{l})$ and ethanol (11.4 g/l) as substrates. At $25^{\text {th }}$ day acetate was completely utilized by bacteria [14]. Steinbusch et al. (2011) conducted experiments using enriched mixed culture, ethanol (4 g/l) and 
acetate (5 g/l) for MCFA production [15]. They reported, acetate was not completely utilized by mixed culture within 117 days.

\section{Ethanol utilization}

\section{Fig. 2}

Ethanol utilization was observed in all the experiments (Fig. 3). Experiments conducted without ethanol (EXP3) also showed little amount of ethanol at $0^{\text {th }}$ day, this may be due to the presence of ethanol in pre-culture medium. Ethanol concentration showed decrement from $0^{\text {th }}$ day $(2.4 \mathrm{~g} / \mathrm{l})$ to end of the experiment, i.e., $3^{\text {rd }}$ day $(1.5 \mathrm{~g} / \mathrm{l}), 8^{\text {th }}$ day $(0.64 \mathrm{~g} / \mathrm{l}), 13^{\text {th }}$ day $(0.4 \mathrm{~g} / \mathrm{l})$, and $15^{\text {th }}$ day $(0.1$ g/l). Experiments conducted only with ethanol (EXP4) showed highest removal at 33 ${ }^{\text {rd }}$ day (73\%) followed by $15^{\text {th }}$ day (38\%), and $6^{\text {th }}$ day $(23 \%)$. Experiments conducted with mixture of acetate and ethanol (EXP1 \& EXP2) showed continuous decrement of ethanol. Both experiments showed similar pattern of ethanol removal and there is no significant difference. In EXP2, ethanol removal by C. kluyveri was in increasing pattern with increasing time, i.e., $23 \%$ removal at $6^{\text {th }}$ day, $32 \%$ removal at $15^{\text {th }}$ day, and $63 \%$ removal at $33^{\text {rd }}$ day. EXP1 also showed good removal of ethanol at $6^{\text {th }}$ day $(21 \%), 15^{\text {th }}$ day $(37 \%)$, and $33^{\text {rd }}$ day $(62 \%)$. Ethanol concentration showed gradual decrement due to utilization of ethanol for chain elongation process. Steinbusch et al. (2011) used ethanol, acetate and enriched mixed culture for MCFA production [15]. They reported that during the active periods, ethanol was consumed fast and extra ethanol was added three times to prevent depletion. After 40 days, ethanol was completely consumed, and the production of butyrate and caproate were stopped. Vasudevan et al. (2014) reported complete utilization of ethanol at $20^{\text {th }}$ day by using two years old enriched mixed culture and effluent contains acetic acid (2.3 g/l) and ethanol as initial substrates [14].

\section{Fig. 3}




\section{Butyric acid production}

Changes in butyric acid concentration was analysed for all the experiments. Butyric acid was produced in all the experiments. Among all the experiments, EXP1 showed high amount of butyric acid due to the presence of BESA (Fig. 4). BESA inhibits the methanogenic process and directs the metabolic pathway towards fatty acids production [15]. Butyric acid production was started from $6^{\text {th }}$ day $(0.12 \mathrm{~g} / \mathrm{l})$, and it was increased at $13^{\text {th }}$ day $(0.86 \mathrm{~g} / \mathrm{l})$. The production was high at $24^{\text {th }}$ day $(4.56 \mathrm{~g} / \mathrm{l})$ followed by $33^{\text {rd }}$ day $(4.11 \mathrm{~g} / \mathrm{l})$, and $20^{\text {th }}$ day $(2.98 \mathrm{~g} / \mathrm{l})$. EXP2 also showed good amount of butyric acid production. Butyric acid production was started from $6^{\text {th }}$ day $(0.24 \mathrm{~g} / \mathrm{l})$, after that it showed continuous increment i.e., at $13^{\text {th }}$ day $(0.95 \mathrm{~g} / \mathrm{l})$, at $20^{\text {th }}$ day $(2.82 \mathrm{~g} / \mathrm{l})$ (Fig. 4). Higher butyric acid production was observed at $33^{\text {rd }}$ day $(3.12 \mathrm{~g} / \mathrm{l})$ and $24^{\text {th }}$ day $(2.93 \mathrm{~g} / \mathrm{l})$. Compared with EXP2, EXP1 showed 1.6 times of higher butyric acid production at $24^{\text {th }}$ day. Experiments conducted with only acetate (EXP3) and only ethanol (EXP4) does not showed significant amounts of butyric acid production. Very little amount of butyric acid $(<0.5 \mathrm{~g} / \mathrm{l})$ was produced after $8^{\text {th }}$ day (data not shown).

Butyric acid is a key precursor for production of MCFA from acetate and ethanol. Some authors reported about production of butyric acid by C. kluyveri. Barker et al. (1945) reported that $C$. kluyveri can metabolize acetic acid and ethanol under anaerobic conditions and produce $\mathrm{H}_{2}$, butyric acid, and caproic acids [13]. The relative yields of the two acids are determined by the relative amounts of acetic acid and ethanol available. If acetic acid is present in excess, a considerable amount of butyric acid is formed, while if ethanol is in excess, caproic acid is the main product. These relations suggest that butyric acid may be an intermediate in the synthesis of caproic acid from acetic acid. This is supported by the observation that ethanol and butyric acid can be converted to caproic acid [13]. Barker et al. (1945) reported that the fact that butyric and caproic 
acids are formed simultaneously rather than successively during part of the fermentation [13]. The general conclusion to be drawn from a comparison of the calculated and observed decrease in the molar activity of acetic acid is that the results support the view that alcohol is oxidized to acetic acid or a closely related compound which is then condensed to butyric and caproic acids.

\section{Fig. 4}

\section{Caproic and caprylic acid production}

In this study, we mainly evaluated the production of two types of MCFA, i.e., caproic acid (C6), and caprylic acid (C8). MCFA production was not observed in the EXP3 and EXP4. EXP1 conducted with BESA showed highest MCFA production, and C6 was the main product (Fig. 5). BESA inhibits the methanogenic process and directs the metabolic pathway towards fatty acids production [15]. For EXP1, C6 production was started from $6^{\text {th }}$ day $(0.65 \mathrm{~g} / \mathrm{l})$, after that it showed gradual increment, i.e., $13^{\text {th }}$ day $(0.79 \mathrm{~g} / \mathrm{l}), 15^{\text {th }}$ day $(1.21 \mathrm{~g} / \mathrm{l})$. Highest production of C6 was observed on $24^{\text {th }}$ day $(3.21 \mathrm{~g} / \mathrm{l})$ followed by $33^{\text {rd }}$ day $(2.86 \mathrm{~g} / \mathrm{l})$, and $20^{\text {th }}$ day $(1.65 \mathrm{~g} / \mathrm{l})$. EXP2 also showed good amount of C6 production. Production of C6 was started at $6^{\text {th }}$ day $(0.34 \mathrm{~g} / \mathrm{l})$, after that it showed increment at $13^{\text {th }}$ day $(0.65 \mathrm{~g} / \mathrm{l})$ and $15^{\text {th }}$ day $(0.98 \mathrm{~g} / \mathrm{l})$ (Fig. 5). Highest production was observed at $33^{\text {rd }}$ day $(2.18 \mathrm{~g} / \mathrm{l})$, followed by $24^{\text {th }}$ day $(2.16 \mathrm{~g} / \mathrm{l})$, and $20^{\text {th }}$ day $(1.24 \mathrm{~g} / \mathrm{l})$.

BESA addition enhanced the MCFA production by 1.48 times at $24^{\text {th }}$ day. Among all the MCFA, C6 was the dominant product and other MCFA were produced in lower amounts. Yin et al., (2017) reported the highest caproate concentration of $8.42 \mathrm{~g} / \mathrm{l}$ from high ethanol strength wastewater with an ethanol/acetate ratio of 10:1 (550 mM total carbon) [16]. Reddy et al. (2017) reported the production of butyrate $(8.2 \mathrm{~g} / \mathrm{l})$, caproate $(8.6 \mathrm{~g} / \mathrm{l})$, heptanoate $(0.7 \mathrm{~g} / \mathrm{l})$, and caprylate $(0.23 \mathrm{~g} / \mathrm{l})$ with mixed culture and synthetic waste under methane inhibition condition [8]. Steinbusch et al. 
(2011) also reported that C6 was the main product in their experiments. Some researchers used cocultures to produce MCFA in their experiments (Table 1) [15]. Kenealy et al. (1995) used cocultures of ruminal cellulolytic bacteria with $C$. kluyveri and produced $2.6 \mathrm{~g} / \mathrm{l}$ of butyric and 4.6 $\mathrm{g} / \mathrm{l}$ of caproic acids from $4.4 \mathrm{~g} / \mathrm{l}$ of ethanol and $6.0 \mathrm{~g} / \mathrm{l}$ of cellulose [17]. Co-culture of mixed ruminal microbes with C. kluyveri converted cellulosic biomass (alfalfa stems or switchgrass herbage) and ethanol to acetate (dominant product), with successively smaller amounts of propionate, butyrate, valerate and caproate (6.1 g/l) over a 48-72 h run time [11].

\section{Fig. 5}

Contrary to the C6 production, C. kluyveri produced lower amount of C8 (Fig. 6). EXP1 and EXP2 produced good amount of C8 (0.53 g/l and 0.36 g/l respectively) at $24^{\text {th }}$ day (Fig. 6). Kucek et al., (2016) reported that in ethanol-fed systems, even-numbered carboxylates (butyrate, caproate) are the predominant products produced via the reverse $\beta$-oxidation pathway[2]. In lactate-fed systems, the even-numbered reverse $\beta$-oxidation products are accompanied by odd-numbered carboxylates (propionate, valerate) [18], which are derived from the competing acrylate pathway that converts lactate into propionate. Our present work also clearly demonstrated that it is feasible to produce MCFA from acetate and ethanol by using C. kluyveri.

\section{Fig. 6}

Anaerobic pure cultures of $C$. kluyveri can produce caproic acid via chain elongation of carboxylic acids through a reversed $\beta$-oxidation pathway [19-21]. This bacterium uses ethanol as a source of carbon, energy, and reducing equivalents to sequentially elongate the carbon chain of carboxylic acids in two-carbon steps i.e., acetate to butyrate to caproate etc. For every five molecules of ethanol that are used for elongation by C. kluyveri, one molecule of ethanol is oxidized to acetate 
for metabolic energy. The ethanol-acetate metabolism is quite unique for anaerobes and can be described by three coupled reactions [10]. First, ethanol is converted to acetate producing NADH and ATP via substrate level phosphorylation. Second, the fatty acid as acetate is elongated in a cyclic pathway to butyrate using $\mathrm{CoA}, \mathrm{NADH}$ and $\mathrm{FADH}_{2}$ through the coupling of two acetylCoA moieties to butyryl-CoA in a cyclic loop [10]. Third, further chain elongation to caproate occurs from butyrate and ethanol in a similar loop by coupling butyryl-CoA with acetyl-CoA. In every loop two carbons are added up to the original carboxylic acid. This results in products with an even number of carbon atoms. In our experiments, the fermentation occurs in a similar way as first ethanol was consumed, then butyrate and caproate were produced.

\section{Table 1}

\section{pH decrement}

Initial $\mathrm{pH}$ of the growth medium was adjusted to 7 before being added to the flasks. The $\mathrm{pH}$ showed a decreasing trend with respect to time for all the conditions, which might be due to the production of MCFA by bacteria (Fig. 7). EXP1 showed decrement of $\mathrm{pH}$ from 6.72 (at $0^{\text {th }}$ day) to 5.48 (at $33^{\text {rd }}$ day). $\mathrm{pH}$ was decreased from 6.56 (at $0^{\text {th }}$ day) to 5.76 (at $33^{\text {rd }}$ day) for the EXP2. EXP4 also showed decrement of $\mathrm{pH}$ from 6.8 (at $0^{\text {th }}$ day) to 6.01 (at $33^{\text {rd }}$ day). EXP3 showed little decrement of $\mathrm{pH}$ from 6.68 (at $0^{\text {th }}$ day) to 6.18 (at $33^{\text {rd }}$ day). Steinbusch et al. (2011) reported that MCFA product formation was $\mathrm{pH}$ dependent, and higher MCFA production was observed at $\mathrm{pH} 7$ when acetate with $\mathrm{H}_{2}$ and ethanol was fermented at $\mathrm{pH} 5.5$ and $\mathrm{pH} 7$ [15].

\section{Biogas production}

\section{Fig. 7}

Gas samples were taken to measure the $\mathrm{CO}_{2}, \mathrm{H}_{2}$ and $\mathrm{CH}_{4}$ percentages in the produced biogas by analyzing the sample with GC-TCD. Samples were measured at $20^{\text {th }}$ day of the experiment. Biogas 
composition of EXP1 showed, $48 \%$ of $\mathrm{H}_{2}$, and little amount of $\mathrm{CO}_{2}$. $\mathrm{CH}_{4}$ was not observed in EXP1 due to the presence of BESA. EXP2 showed 29\% of $\mathrm{H}_{2}$, little amount of $\mathrm{CO}_{2}$ and $\mathrm{CH}_{4}$. Grootscholten et al. reported that $\mathrm{CH}_{4}$ percentage in the gas phase of the reactors was below one percent [3]. Zhu et al. (2015) also denoted the low $\mathrm{CH}_{4}$ percentage in their studies. They reported the biogas composition of $\mathrm{CO}_{2}(41 \%), \mathrm{H}_{2}(42 \%)$ and $\mathrm{CH}_{4}(0.3 \%)$ by using yellow water as substrate (brown and sticky muddy liquid produced from solid-fermentation contains 96.5 g/l of lactic acid, $50.5 \mathrm{~g} / \mathrm{l}$ of ethanol, and $15.6 \mathrm{~g} / \mathrm{l}$ of glucose) and pit mud as source of inoculum [22]. Agler et al. (2011) also reported slighter amount of $\mathrm{CH}_{4}$ production in the mixed culture reactor using beer from ethanol industry for chain elongation of SCFA [23]. Steinbusch et al. (2011) reported $\mathrm{CO}_{2}$ measurements that were below the detection limit was happened in their experiments [15]. The produced $\mathrm{H}_{2}$ in our experiments might be used for MCFA production. Steinbusch et al. (2011) reported that it is feasible to produce MCFA from acetate using both ethanol and $\mathrm{H}_{2}$ as suitable electron donors [15].

\section{CONCLUSIONS}

Butyrate (C4), caproate (C6), and caprylate (C8) were produced from acetate and ethanol using the bacteria C. kluyveri. Among various conditions, methane-inhibition condition produced highest MCFA than other conditions. C. kluyveri was unable to produce MCFA without substrate and electron donor. $\mathrm{H}_{2}$ gas was produced at highest percentage in biogas. Results denoted that $C$. kluyveri can be used for conversion of highly soluble ethanol into useful products like butyrate and MCFA through chain elongation process. The produced MCFA can be used as antimicrobials, corrosion inhibitors, precursors in biodiesel, and bioplastics production. 


\section{ACKNOWLEDGEMENTS}

This work was supported by funding from Japan Society for the Promotion of Science (JSPS, 15F15352). Dr. M. V. Reddy gratefully acknowledges the JSPS for providing Post-doctoral fellowship (ID No: P15352).

The authors have declared no conflict of interest.

\section{REFERENCES}

1) Angenent, L. T., \& Agler, M. T. (2014). Production of carboxylates and methane from biomass waste, Cornell University, United States Patent, Pub. No. US 2014/0322772 A1, Oct. 30 .

2) Kucek, L. A., Nguyen, M., \& Angenent, L. T. (2016). Conversion of L-lactate into ncaproate by a continuously fed reactor microbiome. Water Research, 93, 163-171.

3) Grootscholten, T. I. M., Borgo, K. D. F., Hamelers, H. V. M., \& Buisman, C. J. N. (2013). Promoting chain elongation in mixed culture acidification reactors by addition of ethanol. Biomass \& Bioenergy, 48, 10-16.

4) Jeon, B. S., Moon, C., Kim, B. C., Kim, H., Um, Y., \& Sang, B. I. (2013). In situ extractive fermentation for the production of hexanoic acid from D-galactitol by Clostridium sp. BS1. Enzyme and Microbial Technology, 53, 143-151.

5) Elsden, S. R., Volcani, B. E., Gilchrist, F. M. C., \& Lewis, D. (1956). Properties of a fatty acid forming organism isolated from the rumen of sheep. Journal of Bacteriology, 72 (5), 681-689.

6) Schievano, T., Pepesciarria, K., Vanbroekhoven, K., Wever, H. D., Puig, S., Andersen, S. J., Rabaey, K., \& Pant, D. (2016). Electro-fermentation-merging electrochemistry with fermentation in industrial applications. Trends in Biotechnology, 34, 866-878.

7) Roy, S., Schievano, A., \& Pant, D. (2016). Electro-stimulated microbial factory for value added product synthesis. Bioresource Technology, 213, 129-139.

8) Reddy, M. V., Mohan, S. V., \& Chang, Y. C. (2017). Sustainable production of medium chain fatty acids (MCFA) with an enriched mixed bacterial culture: microbial characterization using molecular methods. Sustainable Energy \& Fuels. DOI: 10.1039/c7se00467b. 
9) Reddy, M. V., Hayashi, S., Choi, D., Cho, H., \& Chang, Y. C. (2018) Short chain and medium chain fatty acids production using food waste under non-augmented and bioaugmented conditions. Journal of Cleaner Production (accepted).

10) Seedorf, H., Fricke, W. F., Veith, B., Brüggemann, H., Liesegang, H., Strittmatter, A., Miethke, M., Buckel, W., Hinderberger, J., Li, F., Hagemeier, C., Thauer, R. K., \& Gottschalk, G. (2008). The genome of Clostridium kluyveri, a strict anaerobe with unique metabolic features. Proceedings of the National Academy of Sciences of the United States of America, 105, 2128-2133.

11) Weimer, P. J., Nerdahl, M., \& Brandl, D. J. (2015). Production of medium chain volatile fatty acids by mixed ruminal microorganisms is enhanced by ethanol in co-culture with Clostridium kluyveri. Bioresource Technology, 175, 97-101.

12) Diender, M., Stams, A. J. M., \& Sousa, D. Z. (2016). Production of medium-chain fatty acids and higher alcohols by a synthetic co-culture grown on carbon monoxide or syngas. Biotechnology for Biofuels, 9 (82), 1-11.

13) Barker, H. A., Kamen, M. D., \& Bornstein, B. T. (1945). The synthesis of butyric and caproic acids from ethanol and acetic acid by Clostridium kluyveri. Proceedings of the National Academy of Sciences of the United States of America, 31 (12), 373-381.

14) Vasudevan, D., Richter, H., \& Angenent, L. T. (2014). Upgrading dilute ethanol from syngas fermentation to n-caproate with reactor microbiomes. Bioresource Technology, 151, 378-382.

15) Steinbusch, K. J. J., Hamelers, H. V. M., Plugge, C. M., \& Buisman, C. J. N. (2011). Biological formation of caproate and caprylate from acetate: fuel and chemical production from low grade biomass. Energy \& Environmental Science, 4, 216-224.

16) Yin, Y. N., Zhang, Y. F., Karakashev, D. B., Wang, J. L., \& Angelidaki, I. (2017). Biological caproate production by Clostridium kluyveri from ethanol and acetate as carbon sources. Bioresource Technology, 241, 638-644.

17) Kenealy, W. R., Cao, Y., \& Weimer, P. J. (1995). Production of caproic acid by cocultures of ruminal cellulolytic bacteria and Clostridium kluyveri grown on cellulose and ethanol. Applied Microbiology and Biotechnology, 44, 507-513.

18) Weimer, P. J., \& Moen, G. N. (2013). Quantitative analysis of growth and volatile fatty acid production by the anaerobic ruminal bacterium Megasphaera elsdenii T81. Applied Microbiology and Biotechnology, 97, 4075-4081.

19) Hu, X. L., Du, H., \& Xu, Y. (2015). Identification and quantification of the caproic acidproducing bacterium Clostridium kluyveri in the fermentation of pit mud used for Chinese strong-aroma type liquor production. International Journal of Food Microbiology, 214, 116-122. 
20) Yan, S., Wang, S., Qiu, Z., Wei, G., \& Zhang, K. (2015). Optimization of caproic acid production from Clostridium kluyveri $\mathrm{H} 588$ and its application in chinese luzhou-flavor liquor brewing. Advance Journal of Food Science and Technology, 7, 614-626.

21) Weimer, P. J., \& Stevenson, D. M. (2012). Isolation, characterization, and quantification of Clostridium kluyveri from the bovine rumen. Applied Microbiology and Biotechnology, 94 (2), 461-466.

22) Zhu, X., Tao, Y., Liang, C., Li, X., Wei, N., Zhang, W., Zhou, Y., Yang, Y., \& Bo, T. (2015). The synthesis of n-caproate from lactate: a new efficient process for medium-chain carboxylates production. Scientific Reports, 5, 1-9.

23) Agler, M. T., Wrenn, B. A., Zinder, S. H., \& Angenent, L. T. (2011). Waste to bioproduct conversion with undefined mixed cultures: the carboxylate platform. Trends in Biotechnology, 29, 70-78. 


\section{Figure Captions}

Figure 1: Growth curve of C. kluyveri at various experimental conditions.

Figure 2: Acetate concentration decrement at various experimental conditions using the bacteria C. kluyveri.

Figure 3: Variation of ethanol concentration during different experimental conditions.

Figure 4: Production of butyrate with BESA (EXP1) and without BESA (EXP2) using the bacteria C. kluyveri.

Figure 5: Caproate (C6) production using the bacteria C. kluyveri with BESA (EXP1) and without BESA (EXP2).

Figure 6: Caprylate (C8) production using the bacteria C. kluyveri with BESA (EXP1) and without BESA (EXP2).

Figure 7: $\mathrm{pH}$ variation with respect to time during MCFA production under various experimental conditions. 
Table 1: Existing literature reports about caproate (C6) production using pure and cocultures

\begin{tabular}{ccccc}
\hline S No. & Bacterial source & Initial Substrate & C6 production & Reference \\
\hline 1 & C. kluyveri & Acetate \& ethanol & $3.2 \mathrm{~g} / \mathrm{l}$ & This study \\
\hline 2 & C. kluyveri & $\begin{array}{c}\text { Sodium acetate, yeast } \\
\text { extract \& ethanol }\end{array}$ & $3.05 \mathrm{~g} / \mathrm{l}$ & 19 \\
\hline 3 & C. kluyveri & $\begin{array}{c}\text { Ethanol, acetate } \\
\text { \& yeast extract }\end{array}$ & $2.14 \mathrm{~g} / \mathrm{l}$ & 20 \\
\hline 4 & $\begin{array}{c}\text { Co-culture of mixed ruminal } \\
\text { microbes with C. kluyveri }\end{array}$ & $\begin{array}{c}\text { Switch grass herbage } \\
\text { \& ethanol }\end{array}$ & C6-4.9 g/l & 11 \\
\hline 5 & $\begin{array}{c}\text { Co-culture of mixed ruminal } \\
\text { microbes with C. kluyveri }\end{array}$ & $\begin{array}{c}\text { Aalfalfa stems } \\
\text { \& ethanol }\end{array}$ & C6-6.1 g/l & 11 \\
\hline 6 & Clostridium sp. BS-1 & $\begin{array}{c}\text { Galactitol, acetate } \\
\text { \& butyrate }\end{array}$ & $6.96 \mathrm{~g} / \mathrm{l}$ & 4 \\
\hline 7 & C. kluyveri & $\begin{array}{c}\text { Ethanol \& acetate } \\
\text { Purified cellulose } \\
\text { \& ethanol }\end{array}$ & $12.8 \mathrm{~g} / \mathrm{l}$ & 21 \\
\hline 8 & Co-culture of ruminal cellulolytic \\
bacteria with C. kluyveri & C. kluyveri & Ethanol \& acetate & 17 \\
\hline 9 & & $0.0298 \mathrm{~g} / \mathrm{l}$ & 13 \\
\hline
\end{tabular}




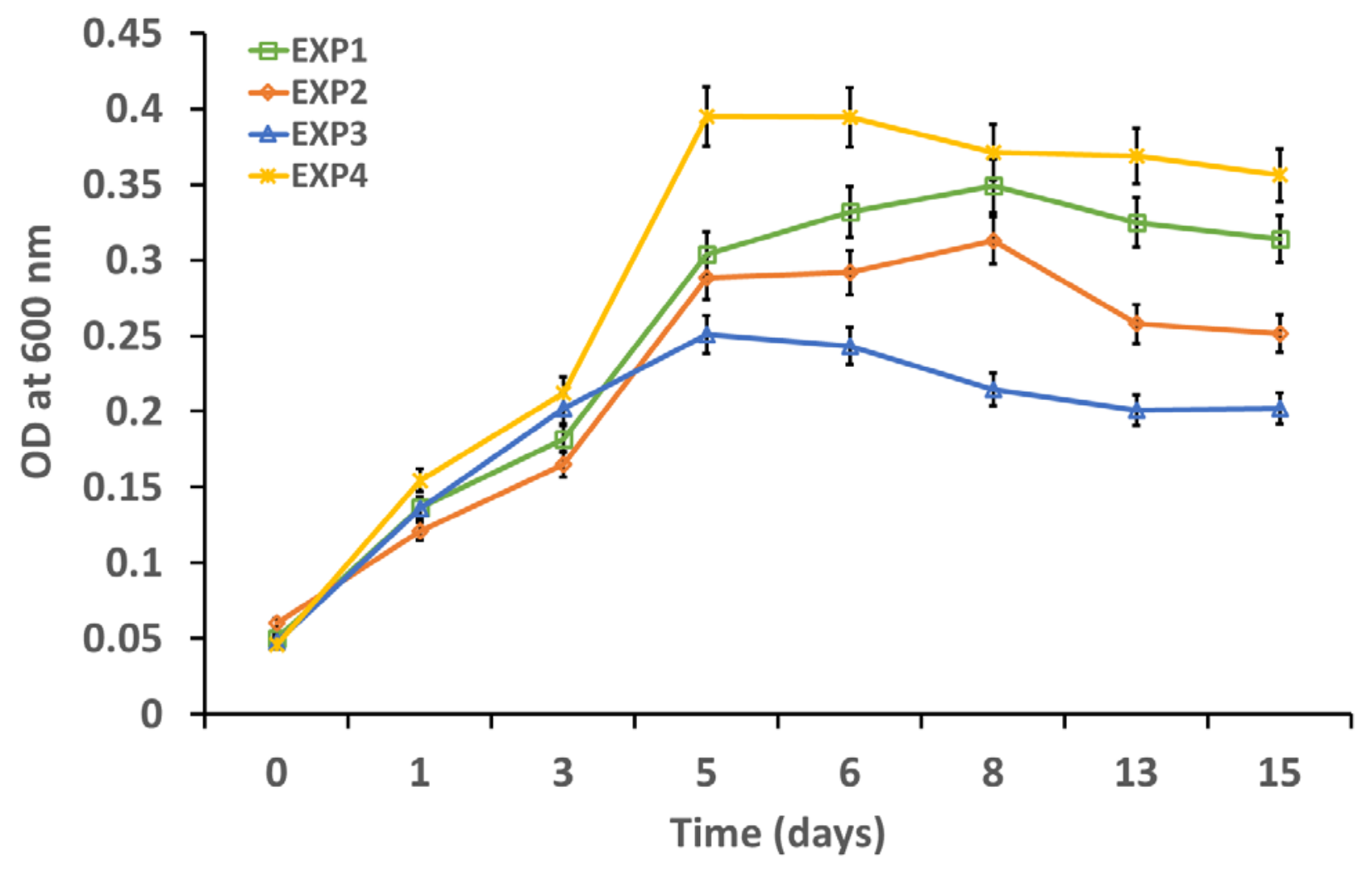

Figure 1 


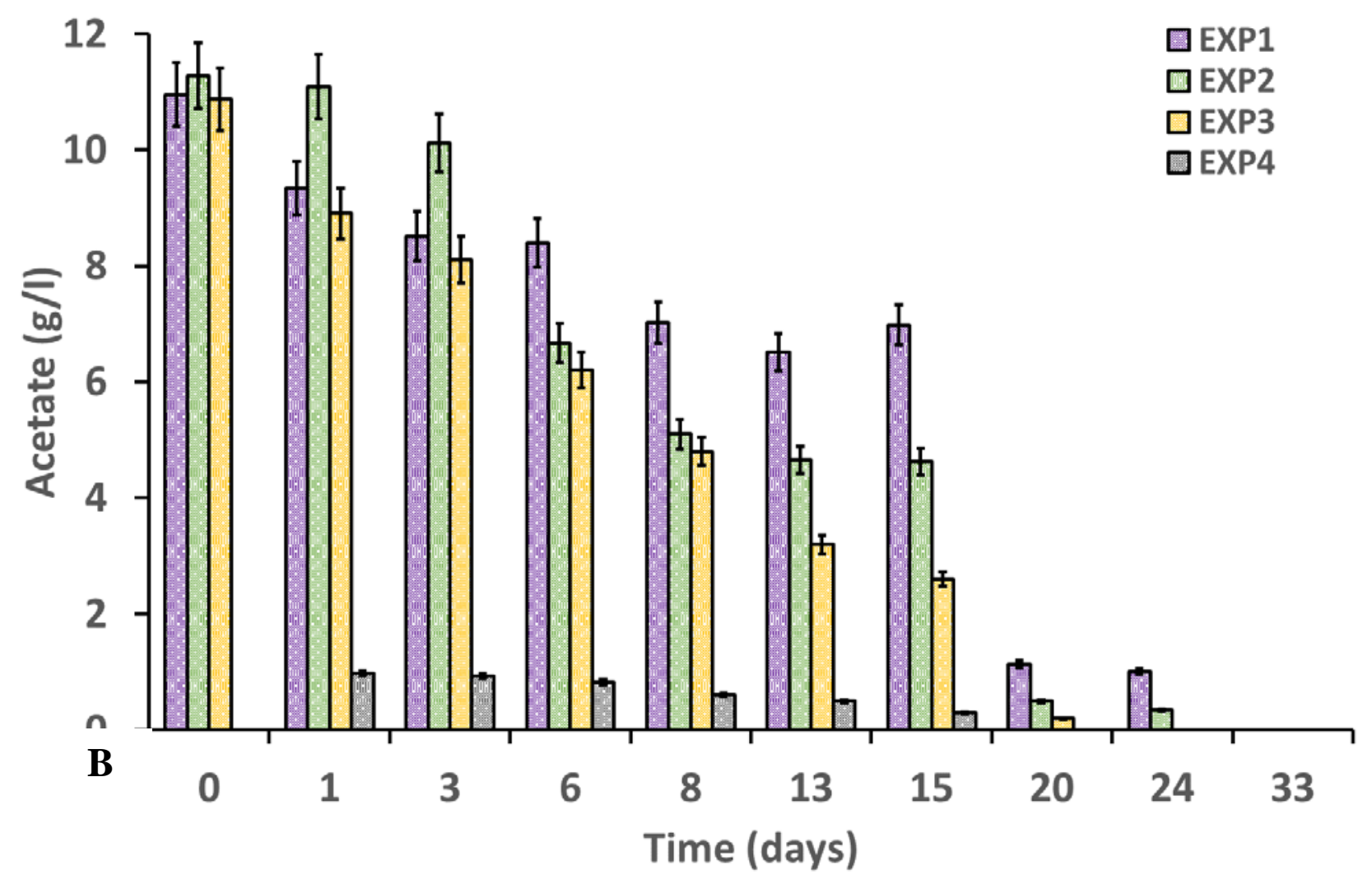

Figure 2 


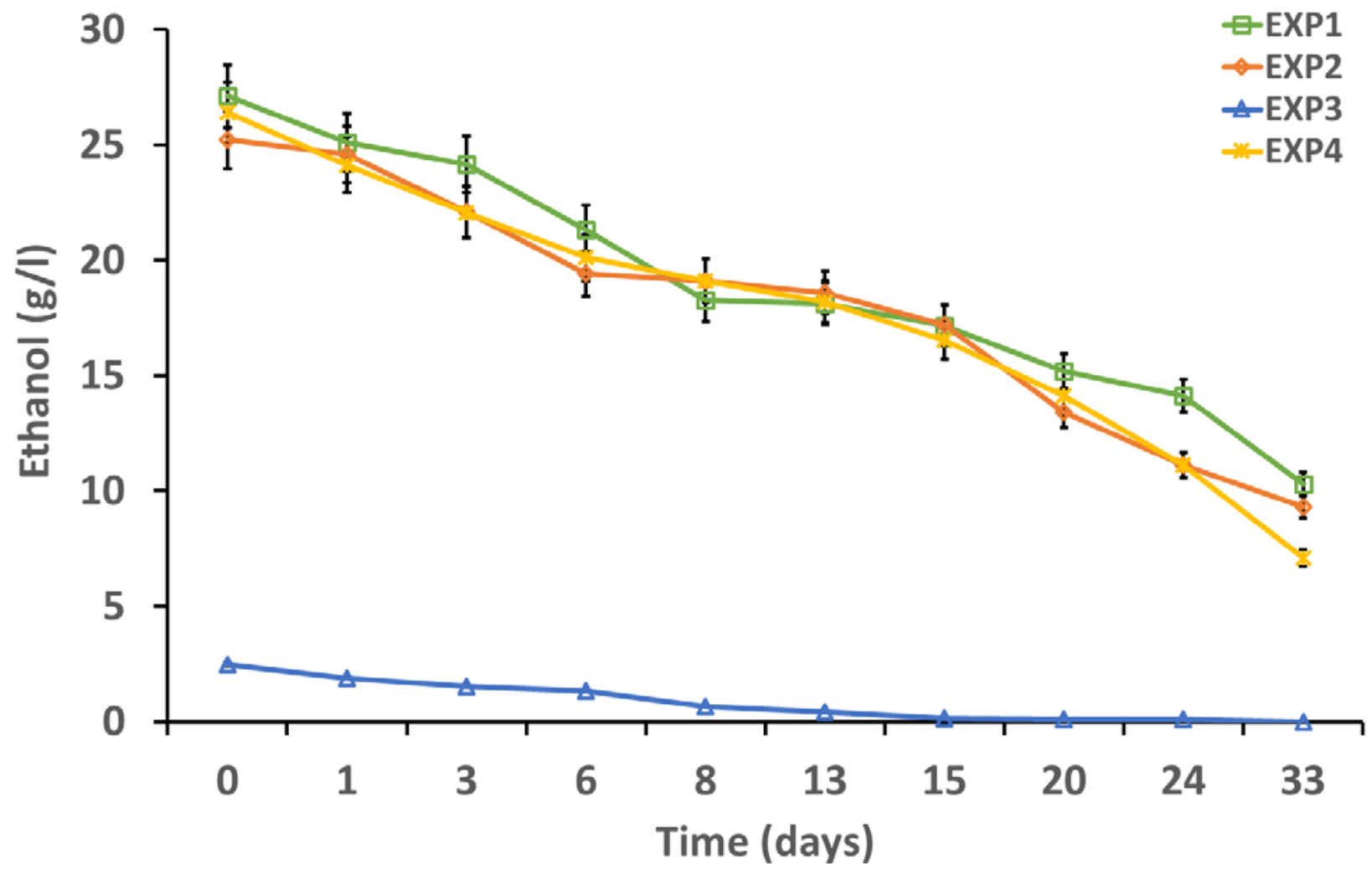

Figure 3 


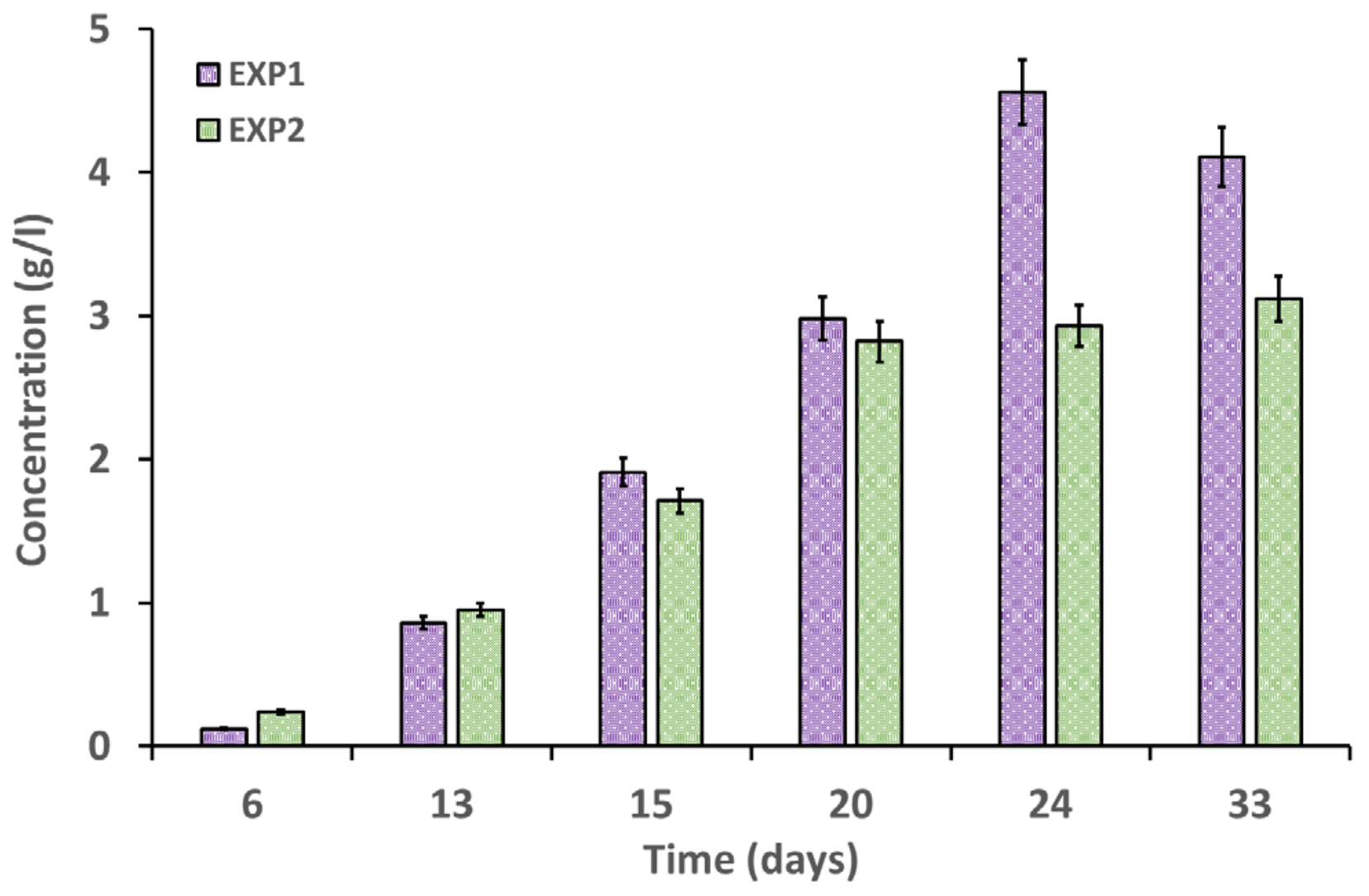

Figure 4 


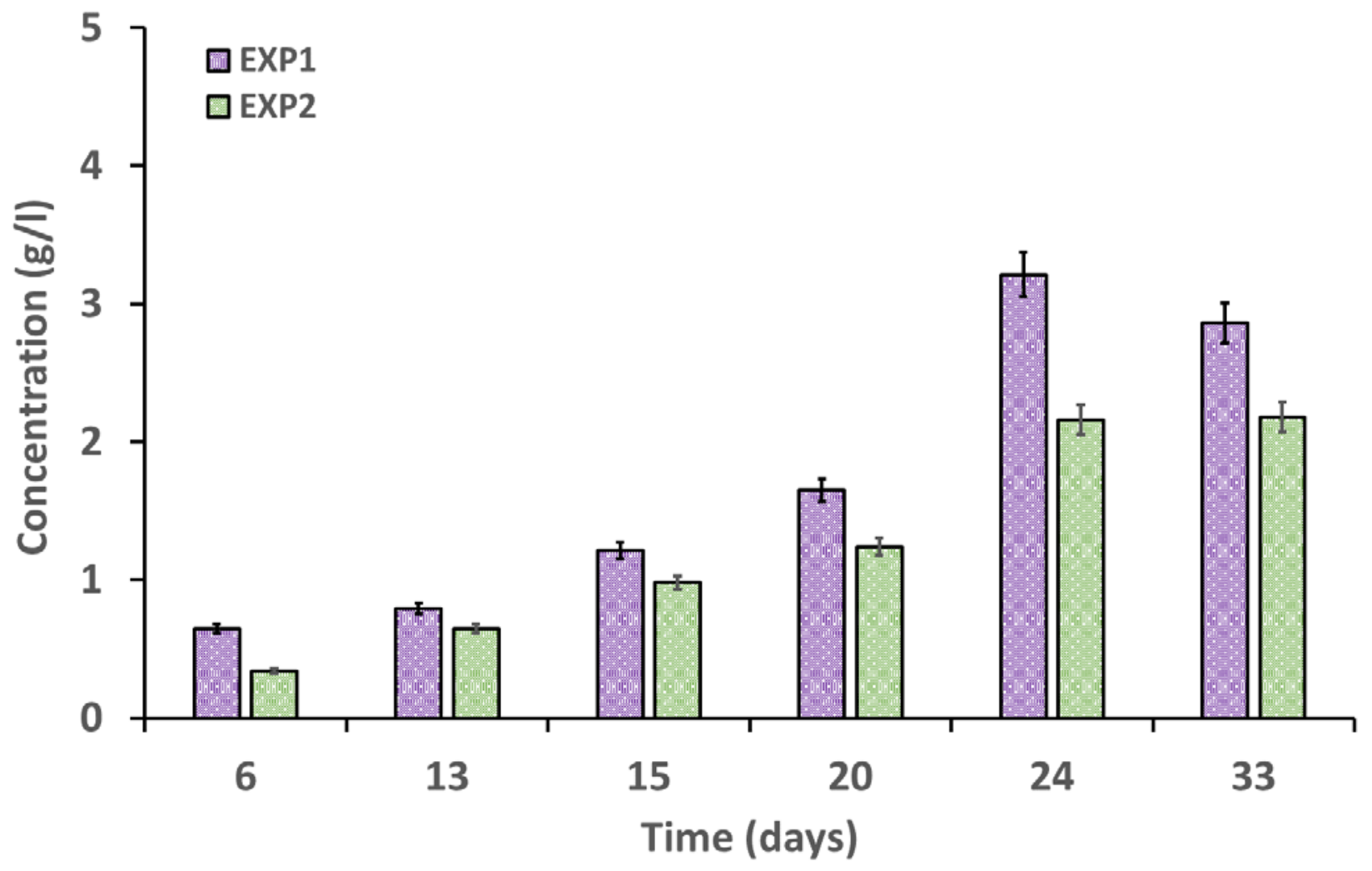

Figure 5 


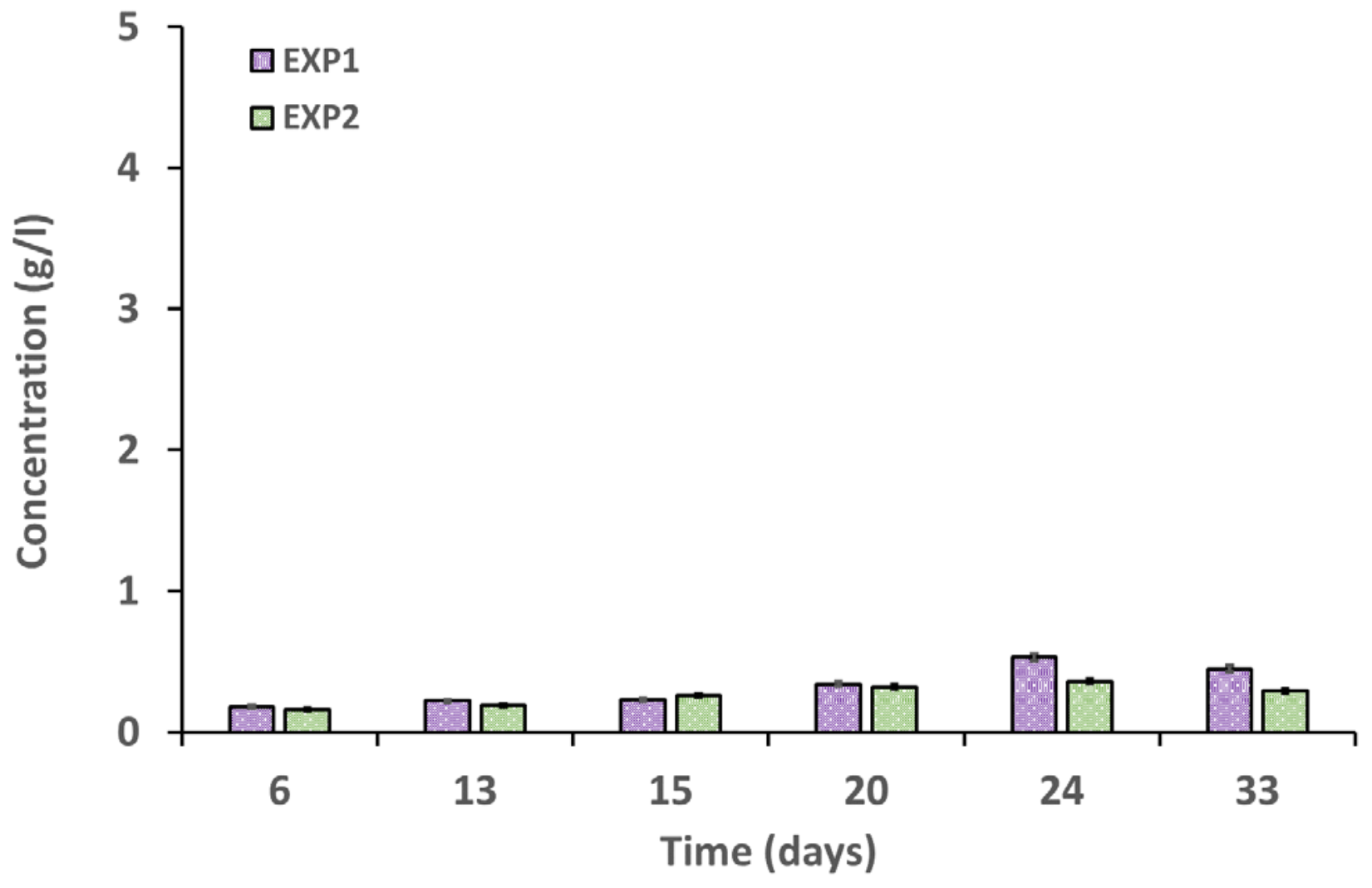

Figure 6 


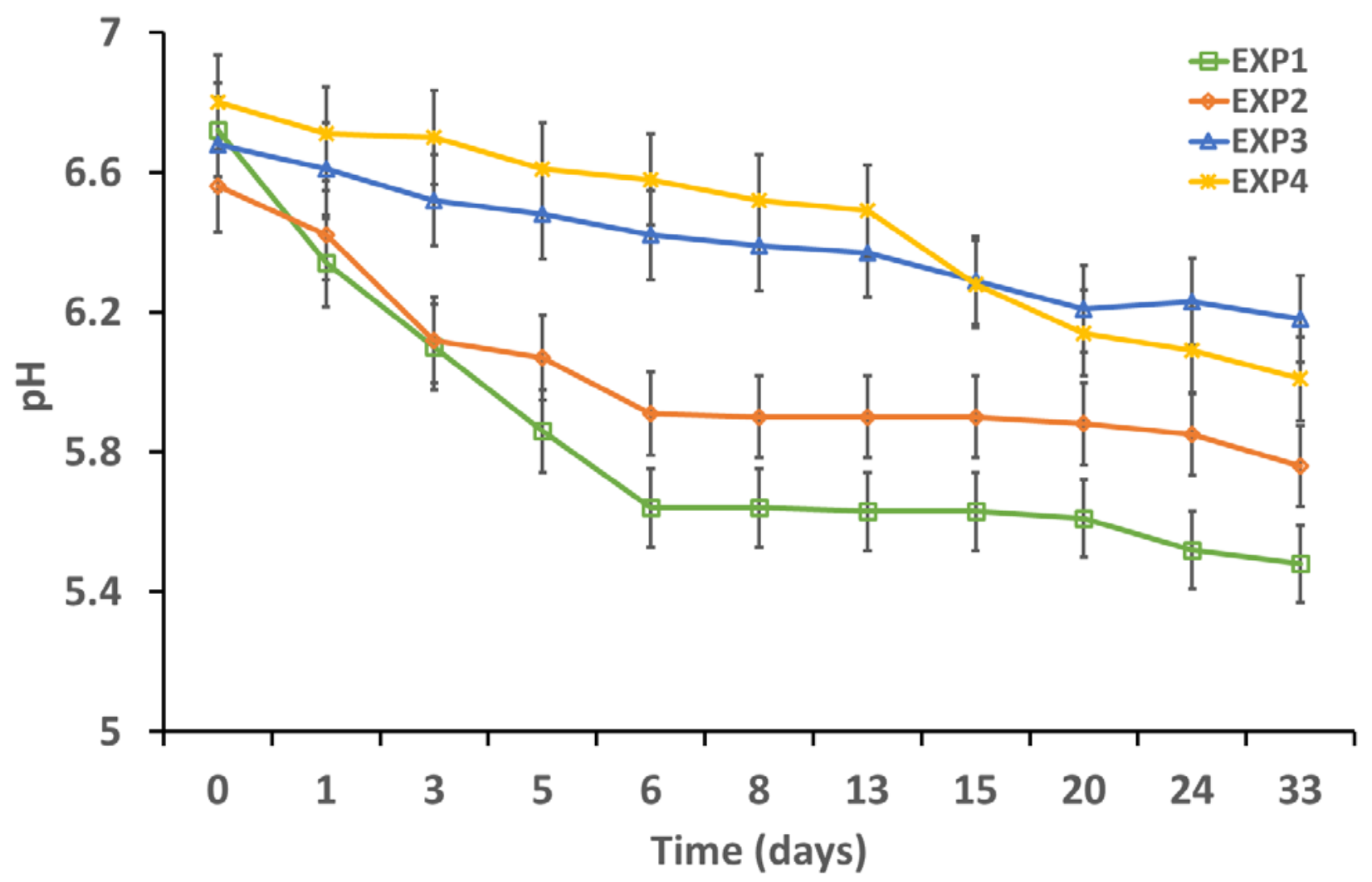

Figure 7 